American Journal of Applied Sciences 6 (4): 616-625, 2009

ISSN 1546-9239

(C) 2009 Science Publications

\title{
Thermal-Mechanical Analysis of a Different Leadframe Thickness of Semiconductor Package under the Reflow Process
}

\author{
S. Abdullah, M.F. Abdullah, A.K. Ariffin and A. Jalar \\ Department of Mechanical and Materials Engineering, \\ University Kebangsaan Malaysia, 43600 UKM Bangi, Selangor Darul Ehsan, Malaysia
}

\begin{abstract}
The copper-based leadframe is practically proven effective in the thermal and reliability of a Quad Flat No Lead (QFN) three dimension (3D) stacked-die semiconductor package. Reducing the copper thickness is understood to present various thermal and reliability failure mode and mechanisms, such as die cracking and delamination. However, no in-depth study has been pursued in order to determine the capability of achieving the product requirements in terms of thermal and reliability in a 3D stacked-die package. The drive towards a Die-Free Package Cost (DFPC) reduction has led the authors to study the used of a thin leadframe in a QFN 3D stacked-die. Hence, the work presents basis for the qualification of a thin leadframe design and also to demonstrate the thermal and reliability performance. Finally, an extensive virtual thermal-mechanical prototyping has to be achieved in order to understand the physics of materials during the assembly and reliability testing of a 3D stacked-die package with a thin leadframe. This design rule was found to be developed in order to prevent a die crack occurrence between die and leadframe in the semiconductor package.
\end{abstract}

Key words: 3D Stacked-die, design, leadframe, QFN, stress, thermo-mechanical

\section{INTRODUCTION}

The reliability of microelectronic packages is a major concern in the electronic industries. Thermalmechanical stress failure in packaging materials is one of the leading causes of the microelectronic packaging component failure and reliability issues. With the periodical switching on and off in the circuit and the variety of environment temperature, the packaging component will experience thermal cycles. Because of the Coefficient Thermal Expansion (CTE) mismatch of the constituent materials, the package undergoes periodic thermal stress and $\operatorname{strain}^{[1]}$. Epoxy Molding Compound (EMC) is widely used as encapsulating material for copper leadframe and die in electronic packaging application. This epoxy material has been chosen because of its superior in thermal-mechanical properties and also lower cost in production. However, the leadframe and encapsulating materials are prone to thermo-mechanical failures, which also lead to the lowcycle fatigue failure ${ }^{[2]}$.

In the semiconductor packaging assembly process, a residual stress has been imposed into the package. The residual stress can give the impact of the package reliability in many aspects. During the temperature cycling, the thermal stress due to the mismatch of Coefficients Thermal Expansion (CTE) between dissimilar materials in the package may cause the initiation of crack and propagation and it may also result to the package failure ${ }^{[3]}$. With the decrease in electronic component volume and the increase in the density of input and output connection, the testing to the actual electronic component thermal-mechanical performance becomes more difficult. In order to solve these related issues, the Finite Element Analysis (FEA) becomes an important tool for analyzing the thermalmechanical reliability of electronic devices and assembly ${ }^{[4]}$. Though a great deal of research work on the solder fatigue has been published, not so much study on the thermo-mechanical fatigue of packaging polymers has been done ${ }^{[5,6]}$.

This study implies the results of FEA for simulating the actual QFN packaging process and the temperature step condition in the Infra Red (IR) reflow process. In addition, a study on the process-induced residual stress and the thermal stress during thermal cycling was also performed, for which this process may cause thermal-mechanical stress on the different leadframe thickness.

Corresponding Author: Shahrum Abdullah, Department of Mechanical and Materials Engineering,

University Kebangsaan Malaysia, 43600 UKM Bangi, Selangor Darul Ehsan, Malaysia

Tel: +60-3-89216518 Fax: +60-3-89259659 
Am. J. Applied Sci., 6 (4): 616-625, 2009

\section{MATERIALS AND METHODS}

Materials properties and constitutive behaviour: The material properties input of the designated QFN package for the proposed FEM approach are shown in Table 1. The Young's modulus properties allow the prediction of material behaviour under a certain load. For instance, the Young's modulus can be used to predict the materials in QFN package that will extend under tension, or to predict the load at which a thin column will buckle under compression. Other calculations should also be required with the use of other material properties, such as the shear modulus, the density and the Poisson's ratio values.

The behaviour of eutectic solder joints is modelled as temperature dependent elastic-plastic and ratedependent creep. The temperature dependence of the Young's modulus (E) is mathematically defined by the following equation ${ }^{[2]}$ :

$$
E(T)=35366-151 T
$$

where the temperature $\mathrm{T}$ is in the unit of Celsius $\left({ }^{\circ} \mathrm{C}\right)$. The solder is assumed to have an elastic-perfect plastic behaviour. The temperature dependent yield stress $\left(\sigma_{y}\right)$ is described by the following expression:

$$
\sigma_{y}(T)=49.2-0.097 \mathrm{~T}
$$

The creep behavior $\left(\dot{\varepsilon}_{\mathrm{cr}}\right)$ for a given material shows a different creep mechanisms that may be operative at different temperatures and stress levels. In order to gain more knowledge in the time-dependent properties of the sample materials, it is a desirable to obtain the relationship between the nanoindentation strain rates $(\varepsilon)$ and the average indentation stress $(\sigma)$ during the holding time. The creep behaviour of a material in QFN package is mathematically defined as the following expression:

$$
\dot{\varepsilon}_{\text {cr }}=C_{1}\left(\frac{E}{T}\right) \cdot\left[\sinh \left(\frac{\alpha \sigma}{E}\right)\right]^{n} \cdot e^{\frac{Q}{K T}}
$$

The EMC that has been used in the QFN package is assumed to have a time-temperature dependent viscoelastic material. The shear modulus is also modelled with a 15 term of the Maxwell model ( $G(t))$, as formulated in Eq. 4:

$$
\mathrm{G}(\mathrm{t})=\mathrm{G}_{\infty}+\sum_{\mathrm{i}=1}^{\mathrm{n}} \mathrm{G}_{\mathrm{i}} \cdot \mathrm{e}^{-\mathrm{t} / \tau_{\mathrm{i}}}
$$

Table 1: Material properties of the designated QFN package

\begin{tabular}{lrcrc}
\hline Material & $\mathrm{E}(\mathrm{GPa})$ & Poisson's ratio & $\mathrm{G}(\mathrm{GPa})$ & $\mathrm{CTE}\left(\mathrm{ppm} /{ }^{\circ} \mathrm{C}\right)$ \\
\hline Leadframe & 120.70 & 0.11 & 52.500 & 16.63 \\
Epoxy & 7.50 & 0.25 & 0.340 & 8.00 \\
Mother Die & 28.00 & 0.26 & 8.000 & 3.61 \\
DAF & 1.66 & 0.26 & 0.038 & 17.00 \\
Daughter Die & 28.00 & 0.26 & 8.000 & 3.61 \\
Mold compound & 8.00 & 0.35 & 7.000 & 3.90 \\
\hline
\end{tabular}

where $G_{\infty}$ is the equilibrium shear modulus, $\tau_{i}$ and $G_{i}$, are the relaxation time and stiffness coefficient corresponding to the term in the Maxwell model, respectively. The temperature effect is considered with the assumption of having a thermorheologically simple material. This situation can be explained using the William-Landel-Ferry (WLF) equation, i.e:

$$
\log \mathrm{a}_{\mathrm{T}}=\frac{-\mathrm{C}_{1}\left(\mathrm{~T}-\mathrm{T}_{\mathrm{ref}}\right)}{\mathrm{C}_{2}+\left(\mathrm{T}-\mathrm{T}_{\mathrm{ref}}\right)}
$$

where, $T_{\text {ref }}$, is the reference temperature and both $C_{1}$ and $\mathrm{C}_{2}$, are the material constants. For this case, the Possion's ratio is assumed to be a constant value, i.e., $0.30^{[1]}$. In order to complete the analysis of this study, the ANSYS ${ }^{\circledR}$ software was then used to simulate the QFN package computational analysis based on the listed mathematical model.

Geometry and FEM mesh: For the finite element modeling purposes, the QFN model was designed using a fully matrix QFN 3D stacked-die package. In this study, the two same size models of QFN packages were used for the analysis. The schematic diagrams of the chosen QFN 3D stacked-die package are shown in Fig. 1a and 2a. All QFN packages were having the package thickness at $0.85 \mathrm{~mm}$. The size of this was selected since it can give higher performance in terms of the reliability testing. However, the differences between two selected models were only on the leadframe thickness and mold cap. Fig. 1 shows the leadframe thickness of $0.20 \mathrm{~mm}$ and the mold cap thickness of $0.65 \mathrm{~mm}$. On the other hand, Fig. 2 shows the leadframe thickness of $0.15 \mathrm{~mm}$ and the mold cap thickness of $0.70 \mathrm{~mm}$. Both QFN package, such as epoxy, mother die, die attach film (DAF) and daughter die were fabricated from the same materials for both leadframe thickness.

Using ANSYS ${ }^{\circledast}$, one quarter of the structure for the 3 -D modeling was modeled. The finite element mesh is presented in Fig. $1 \mathrm{~b}$ and $2 \mathrm{~b}$. The boundary conditions that has been used in the FEA are based on the origin coordinate, i.e., $\mathrm{z}=\mathrm{x}=\mathrm{y}=0$, while the nodes along the symmetric axis are based on the symmetrical boundary conditions. 


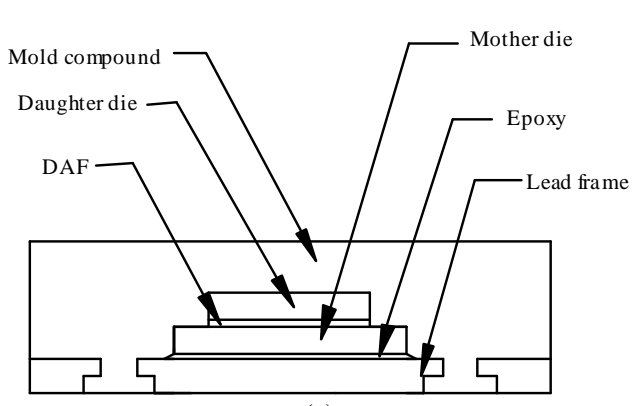

(a)

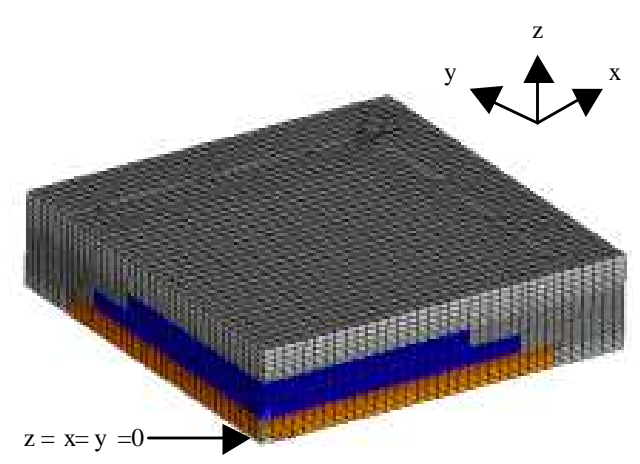

(b)

Fig. 1: (a) A schematic diagram of the QFN package for leadframe thickness of $0.20 \mathrm{~mm}$, (b) Finite element mesh of a QFN package

Thermal loading: In order to simplify the analysis for the simulation process, which is presented in this study, the thermal loading history includes only the cooling down process from the curing procedure, reflow soldering process and three temperature cycles. Table 2 shows the temperature profile that has been performed in the entire simulation ${ }^{[7]}$. The distribution of this profile is illustrated in Fig. 3. The reflow process is important testing in industrial because the result from the reflow process can been showing similar result compared actual application.

Referring to Fig. 3, the reflow process is assumed to have no longer than four hours to three times cycles of the appropriate reflow conditions, as defined in Table 2 and 3, after the removal from the temperature and humidity chamber. There are optimum period times of the reflow process that is needed to relate the actual IC package application. If the timing between the removal from the temperature and humidity chamber and the initial reflow cannot be met, then the parts must be rebaked and resoaked. This step is intended to remove moisture from the package so that it will be dry. The moisture soak means that the packages are placed in a clean, dry, shallow container so that the package bodies do not touch or overlap each other. The parts for

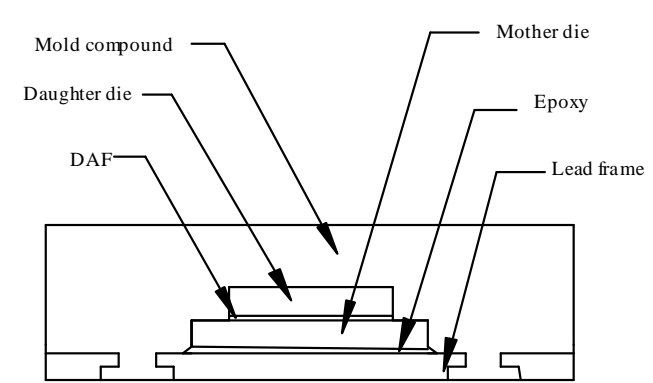

(a)

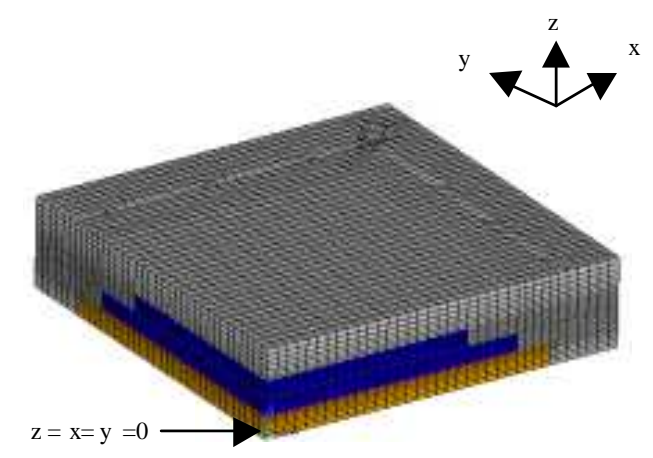

(b)

Fig. 2: (a) A schematic diagram of the QFN package for leadframe thickness of $0.15 \mathrm{~mm}$, (b) Finite element mesh of a QFN package

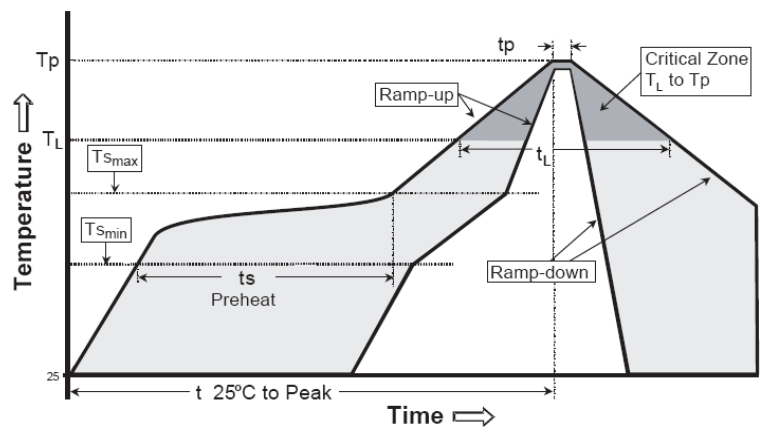

Fig. 3: The classification of the reflow profiles ${ }^{[7]}$

Table 2: Process Reflow of QFN package ${ }^{[7]}$

\begin{tabular}{lc}
\hline Profile Feature & Pb-Free Assembly \\
\hline Average ramp-up rate $\left(\mathrm{Ts}_{\max }\right.$ to $\left.\mathrm{T}_{\mathrm{p}}\right)$ & $3^{\circ} \mathrm{C} / \mathrm{sec}$ max. \\
Preheat & $150^{\circ} \mathrm{C}$ \\
- Min Temperature $\left(\mathrm{Ts}_{\min }\right)$ & $200^{\circ} \mathrm{C}$ \\
- Max Temperature $\left(\mathrm{Ts}_{\max }\right)$ & $60-180 \mathrm{sec}$ \\
- Time $\left(\mathrm{ts}_{\min }\right.$ to ts $\left.\mathrm{s}_{\max }\right)$ & \\
Time maintained above: & $217^{\circ} \mathrm{C}$ \\
- Temperature $\left(\mathrm{T}_{\mathrm{L}}\right)$ & $60-150 \mathrm{sec}$ \\
- Time $\left(\mathrm{t}_{\mathrm{L}}\right)$ & $260+0^{\circ} \mathrm{C}$ \\
Peak/classification temperature $\left(\mathrm{T}_{\mathrm{p}}\right)$ & $20-40 \mathrm{sec}$ \\
Time within 5 ${ }^{\circ} \mathrm{C}$ of actual Peak Temperature $\left(\mathrm{t}_{\mathrm{p}}\right)$ & $6^{\circ} \mathrm{C} / \mathrm{sec} \max$ \\
Ramp-down rate & $8 \mathrm{~min} \max$ \\
Time $25^{\circ} \mathrm{C}$ to Peak Temperature
\end{tabular}


Am. J. Applied Sci., 6 (4): 616-625, 2009

Table 3: Results for IR Reflow QFN packages in displacements used leadframe 0.20 and $0.15 \mathrm{~mm}$

\begin{tabular}{lcr}
\hline & \multicolumn{2}{c}{ Stress distribution } \\
& $\begin{array}{l}\text { Displacement of } \\
0.20 \text { mm leadframe } \\
\text { thickness }(\mu \mathrm{m})\end{array}$ & $\begin{array}{l}\text { Displacement of } \\
0.15 \text { mm leadframe } \\
\text { thickness }(\mu \mathrm{m})\end{array}$ \\
Step/ Stress & -1.180 & -1.030 \\
\hline Ambient temperature & -0.393 & -0.343 \\
Preheat $\mathrm{T}_{\mathrm{s}}$ min at $150^{\circ} \mathrm{C}$ & 0.000 & 0.000 \\
Stress Free at $175^{\circ} \mathrm{C}$ & 0.292 & 0.261 \\
Preheat $\mathrm{T}_{\mathrm{s}}$ max at $200^{\circ} \mathrm{C}$ & 0.461 & 0.427 \\
Time Maintained, & & \\
$\mathrm{T}_{\mathrm{L}}$ max at $217^{\circ} \mathrm{C}$ & 0.985 & 0.865 \\
Peak/Classification & & -1.030 \\
Temperature, $\mathrm{T}_{\mathrm{p}}$ at $260^{\circ} \mathrm{C}$ & & \\
Finish IR Reflow at $25^{\circ} \mathrm{C}$ & -1.180 & \\
\hline
\end{tabular}

the etching temperature should be handled using the proper Electronic Static Discharge (ESD) procedures. The time between reflows shall be within five minutes at the minimum and 60 minutes at the maximum ${ }^{[7]}$.

\section{RESULTS AND DISCUSSION}

The IR reflow process involved with 6 steps for the difference thermal loading and 1 step for the stress free process. Because of the higher curing temperature value of $260^{\circ} \mathrm{C}$ and the mismatch of the coefficients of thermal expansion between dissimilar materials, the residual stress in the leadframes was already induced at the initial stages of the thermal loading. Table 3 shows the numerical simulation result for displacements. In addition, Table 4 shows the results of the von-Mises stresses for the leadframe thickness of 0.20 and 0.15 $\mathrm{mm}$. In this study, the focusing scope of the analysis is more on the stress that was distributed between two types of leadframe thickness.

In general, the semiconductor industries have a standard procedure fore testing the reliability criteria on the IC packages. The IR reflow process has been recognized to be one of the reliability test procedure and it has been applied after the Moisture Sensitivity Level (MSL) witerion. This process flow involved the die mounting, the wire bonding, the molding and the singulation. The EMC elements were then deactivated during die attach process at $175^{\circ} \mathrm{C}$ and this temperature is a reference for the minimum stress temperature ${ }^{[1-3]}$, as defined by the temperature profile step in Table 2 . The EMC element was reactivated at molding temperature of $175^{\circ} \mathrm{C}$ and it was then cooled to $25^{\circ} \mathrm{C}$. It is meant that the element birth and death option can meet the simulation equipments. At the die mounting and temperature, the package components are assumed to be stress free.
Table 4: Results for IR Reflow QFN packages in von Mises stress used leadframe 0.20 and $0.15 \mathrm{~mm}$

\begin{tabular}{lcc}
\hline Step/ Stress & \multicolumn{2}{c}{ Stress Distribution } \\
& $\begin{array}{l}\text { von Mises stress of } \\
0.20 \mathrm{~mm} \text { leadframe } \\
\text { thickness }(\mathrm{GPa})\end{array}$ & $\begin{array}{l}\text { von Mises stress of } \\
0.15 \mathrm{~mm} \text { leadframe } \\
\text { thickness (GPa) }\end{array}$ \\
\hline Ambient temperature & 1.020 & 0.974 \\
Preheat $\mathrm{T}_{\mathrm{s}}$ min at $150^{\circ} \mathrm{C}$ & 0.277 & 0.264 \\
Stress Free at $175^{\circ} \mathrm{C}$ & 0.003 & 0.025 \\
Preheat $\mathrm{T}_{\mathrm{s}}$ max at $200^{\circ} \mathrm{C}$ & 0.219 & 0.206 \\
Time Maintained, & 0.323 & 0.305 \\
$\mathrm{~T}_{\mathrm{L}}$ max at $217^{\circ} \mathrm{C}$ & & 0.604 \\
Peak/Classification & 0.664 & 0.970 \\
Temperature, $\mathrm{T}_{\mathrm{p}}$ at $260^{\circ} \mathrm{C}$ & & \\
Finish IR Reflow at $25^{\circ} \mathrm{C}$ & 1.020 & \\
\hline
\end{tabular}

Fig. 4 and 5 shows the leadframe view on different step temperature condition between leadframe thickness $0.20 \mathrm{~mm}$ and $0.15 \mathrm{~mm}$.

Fig. 4 shows the result of the FE modelling for the displacement contour on QFN with the leadframe thickness of $0.20 \mathrm{~mm}$. Step 1 shows the brown counter at the surface DAP and red counter at the lead on the leadframe. For the Step 2, the contour colour at the middle on the leadframe surface. Step 3 shows the blue contour at the leadframe that mean stress free at leadframe. Step 4, 5 and 6 show the colour contour not too different for the etching step. Step 7 was the last step in step condition. Step 7 shows the brown contour, which is at the same contour colour as Step 1.

Fig. 5 shows the result of the FE modelling for displacement on QFN package with leadframe thickness of $0.15 \mathrm{~mm}$. The colour contour exhibited in Fig. 5 where almost similar to the colour contour of the distribution in Fig. 4. It is because of the numerical result was seemingly similar for etch step on both leadframe thickness.

Fig. 6 shows the displacement $(\mu \mathrm{m})$ between two different leadframe thicknesses versus step temperature condition. In Fig. 6, the starting step condition is Step 1, displacements for 2 types of leadframe is negative which meant the leadframe was under shrinking condition. The leadframe thickness of $0.20 \mathrm{~mm}$ has show more shrink compared to the leadframe thickness of $0.15 \mathrm{~mm}$. Step 2 shows the situation of no different in the shrinking behaviour for both leadframes, as the temperature of Step 2 was approaching the reference temperature. In Step 3, no displacement has been found in the simulation and it was caused by the temperature at this step was having a stress free condition. After applying Step 4, the leadframes were found to be under expanse and the value for the displacement became positive. It is because of the temperature in Step 4 were higher than the reference temperature and it mean that the leadframe absorbed more heat. In Step 5, 

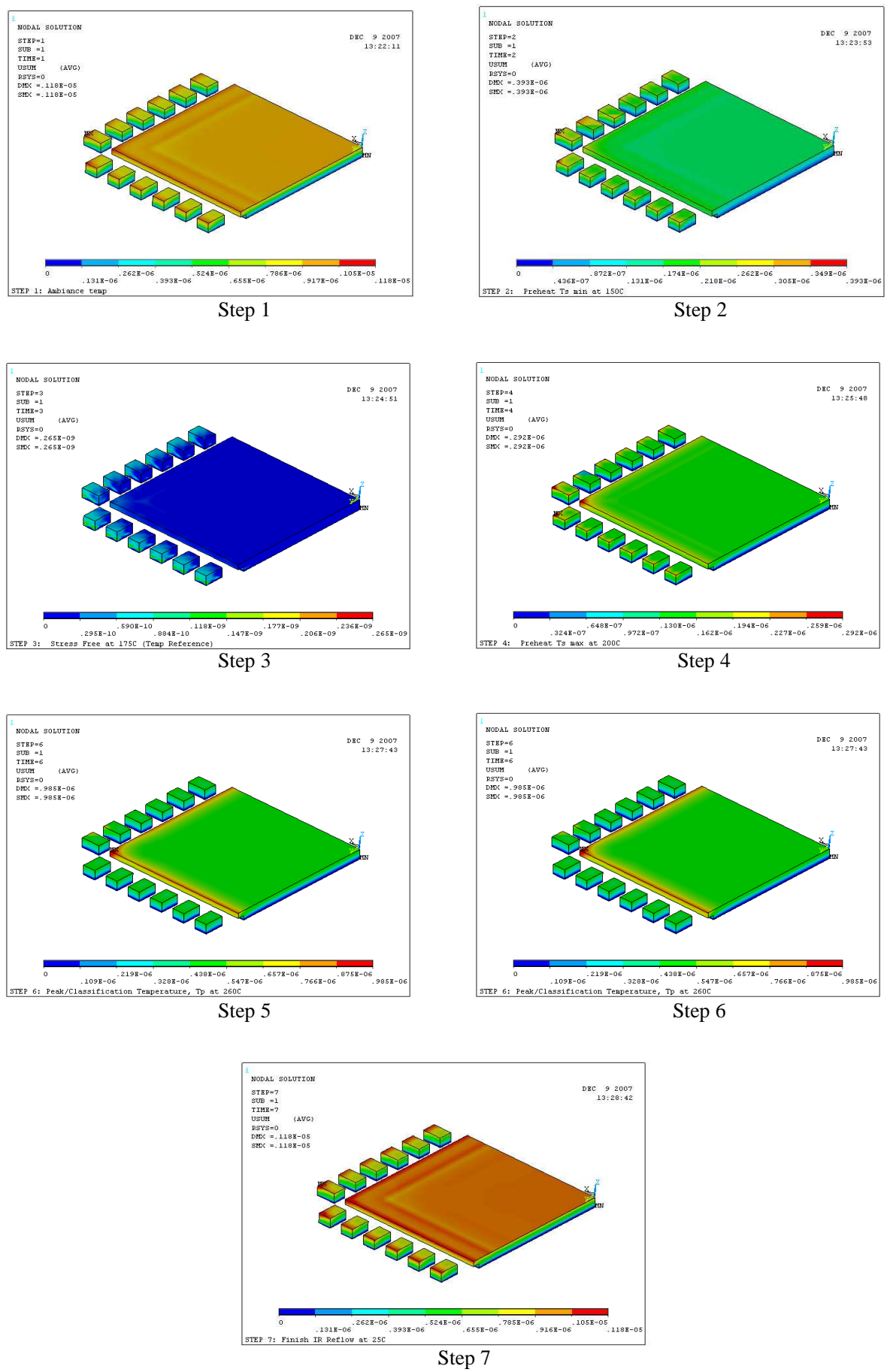

Fig. 4: Results of the displacement contour on QFN package used leadframe thickness of $0.20 \mathrm{~mm}$ for etch steps condition

the displacement for the leadframe thickness of 0.20 $\mathrm{mm}$ was $0.461 \mu \mathrm{m}$ and it was slightly higher than leadframe $0.15 \mathrm{~mm}$ for which the value was only 0.427 $\mu \mathrm{m}$. In Step 6, the maximum displacement distribution was shown and it was at the maximum temperature of $260^{\circ} \mathrm{C}$ for IR Reflow. In Step 7, the temperature was 

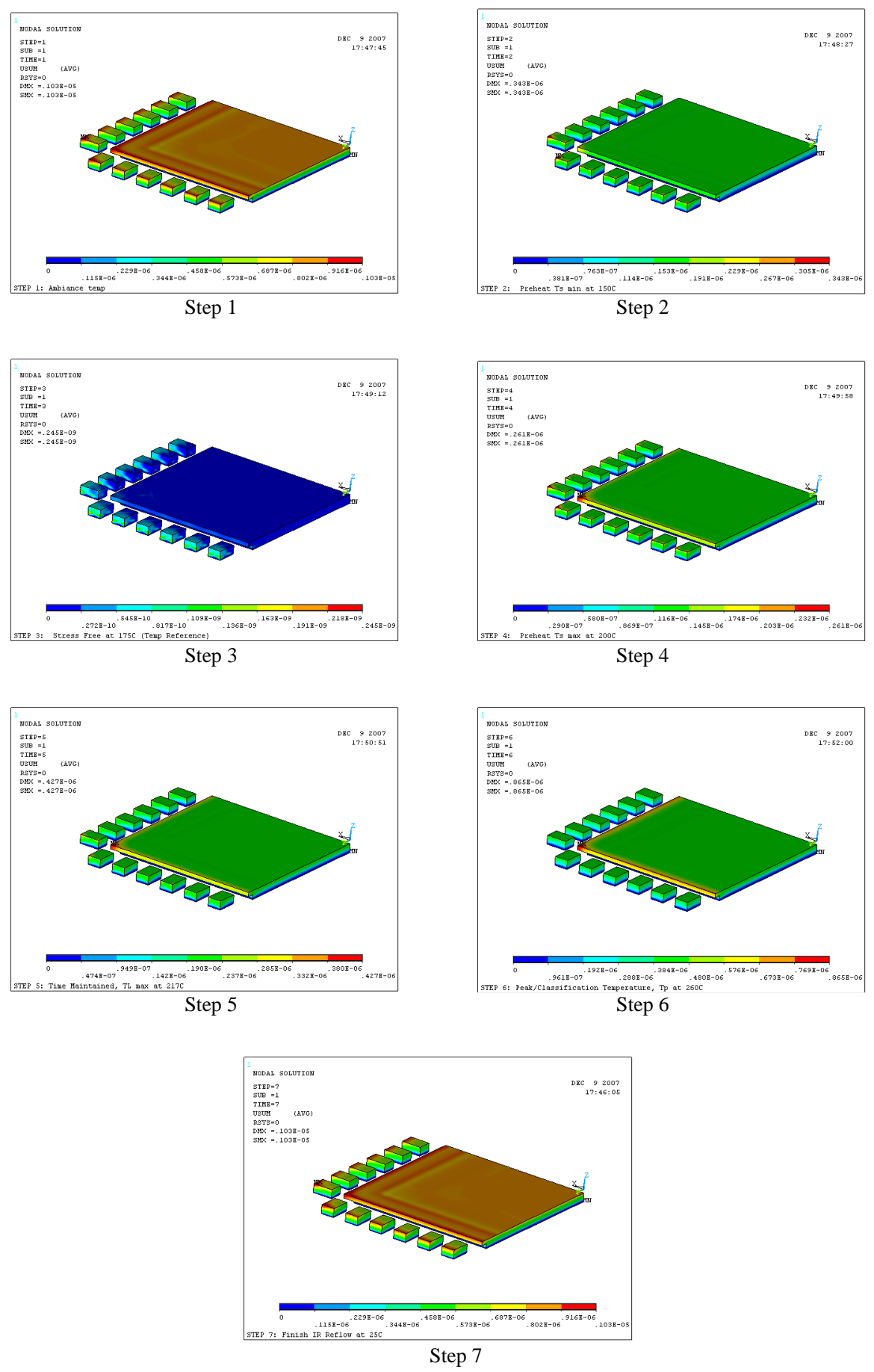

Fig. 5: Results of the displacement contour on QFN package used leadframe thickness of $0.15 \mathrm{~mm}$ for etch steps condition

reducing to $25^{\circ} \mathrm{C}$ and this condition shown the leadframe thickness $0.20 \mathrm{~mm}$ highly risks giving package crack. It is because; the leadframe thickness
$0.20 \mathrm{~mm}$ has maximum expanse reduction to maximum shrink in a short time.

In this reflow case study and analysis, the $0.20 \mathrm{~mm}$ 
Am. J. Applied Sci., 6 (4): 616-625, 2009

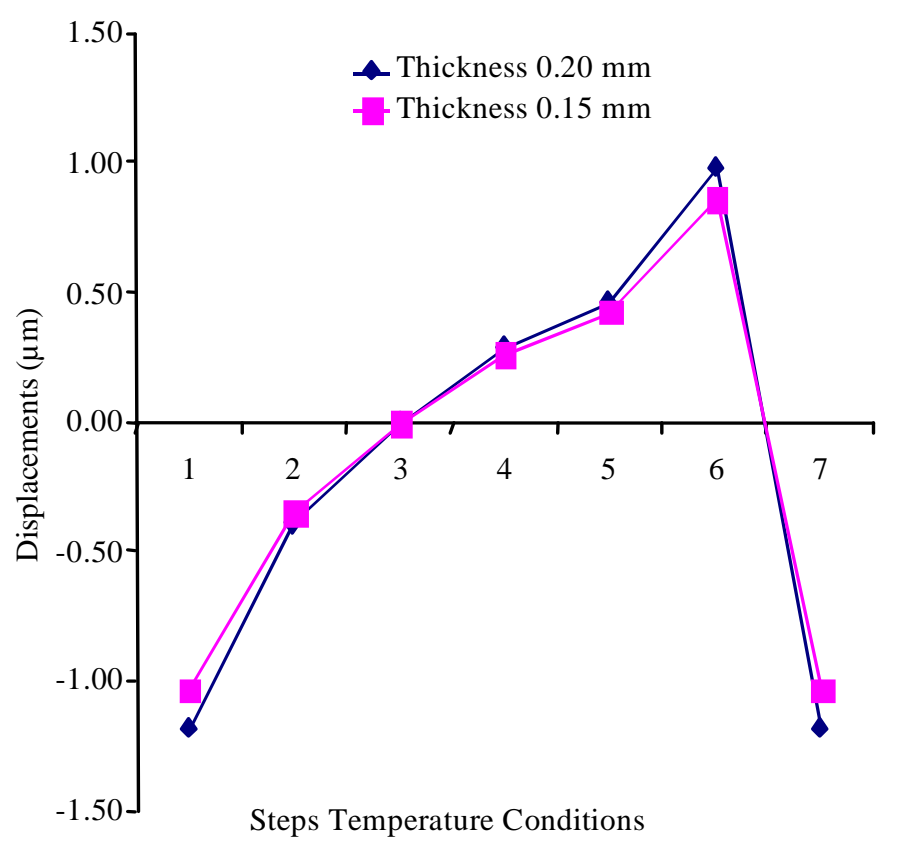

Fig. 6: A plot of displacement for different leadframe thickness versus the reflow stages

leadframe thickness has been found to produce displacement compared to the $0.15 \mathrm{~mm}$ leadframe thickness. Larger displacement of the leadframe can lead to the failure of other component in the package. According to the simulation, the leadframe thickness $0.20 \mathrm{~mm}$ can give more risk for die crack and also the delamination between the die and leadframe.

Fig. 7 shows the result of the finite element modelling based on the von-Mises stress of the QFN package with $0.20 \mathrm{~mm}$ leadframe thickness. Step 1 shows the green contour at the bottom of the leadframe, that mean has medium stress at the bottom of leadframe. Step 2 shows the light blue contour and Step 3 shows the blue contour at the leadframe, because the stress has been reducing to stress free. Step 3 was identified as a stress free on the step condition, because the temperature in this step same to temperature reference. Step 4, 5 and 6 show the colour contour not to different for etch step. Step 7 was the last step in this process and it shows the same contour as in Step 1.

Fig. 8 shows the result of the FEA based on the von-Mises stress of the QFN unit with $0.15 \mathrm{~mm}$ leadframe thickness. The colour contour in Fig. 8 likely similar then the colour contour in Fig. 7. It is because, the numerical result was not to difference for etch step on both leadframe thickness.

The von Mises stress, $\sigma_{v}$, is the scalar function of the stress tensor that gave an approximation for the overall magnitude of the tensor. It allows the onset and amount of plastic deformation under triaxial loading to be predicted from the results of a simple uniaxial tensile test. It is most applicable to a ductile material analysis. The von Mises stresses can then be used to predict failure by ductile tearing. However, it is not appropriate for failure by crack propagation or fatigue, which depends on the maximum principal stress.

In this case, the maximum value of the von Mises stress was obtained with the analysis of the $0.20 \mathrm{~mm}$ leadframe thickness, when compared to the $0.15 \mathrm{~mm}$ leadframe. In Fig. 9, two steps were found to have the maximum value of von Mises stress, i.e., Step 1 and Step 7. The finding has been found due to the difference between the reference temperature and the ambient temperatures for which they were higher when compared to another temperature step. It was also observed that higher thickness of leadframe gave higher value of von-Mises stresses. However, the maximum value of the von Mises stress is $0.974 \mathrm{GPa}$ was acceptable, as this value was still lower than the Young's modulus of the leadframe, i.e., at E, $120 \mathrm{GPa}$.

The leadframe thickness of $0.15 \mathrm{~mm}$ is proposed to be a new design for a semiconductor package particularly for QFN package. It is seemed to be better quality and performance compared to the $0.20 \mathrm{~mm}$ leadframe thickness ${ }^{[8,9]}$. In actual condition, the fabrication of $0.15 \mathrm{~mm}$ leadframe thickness may incurve with costs then the $0.20 \mathrm{~mm}$ thickness. 
Am. J. Applied Sci., 6 (4): 616-625, 2009
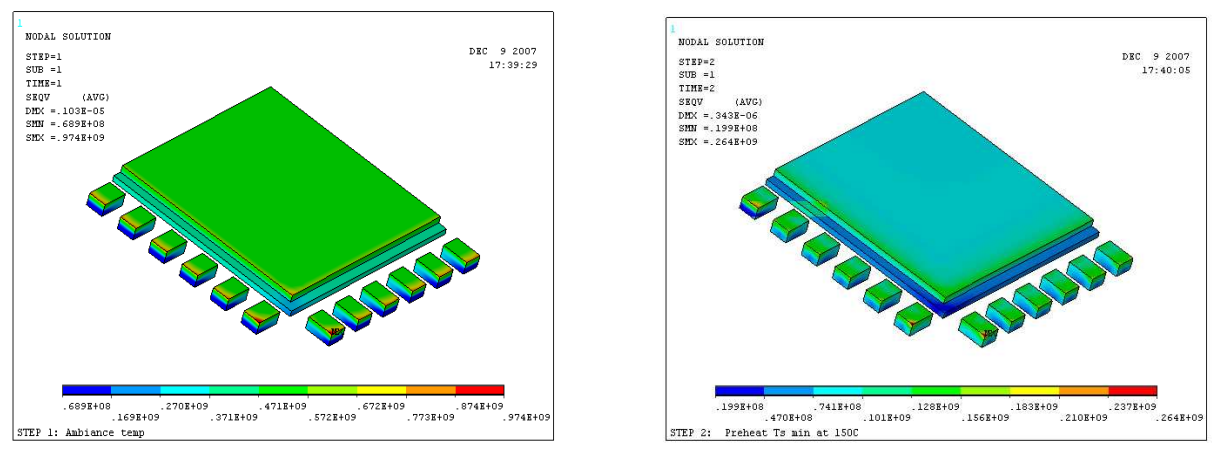

Step 1

Step 2

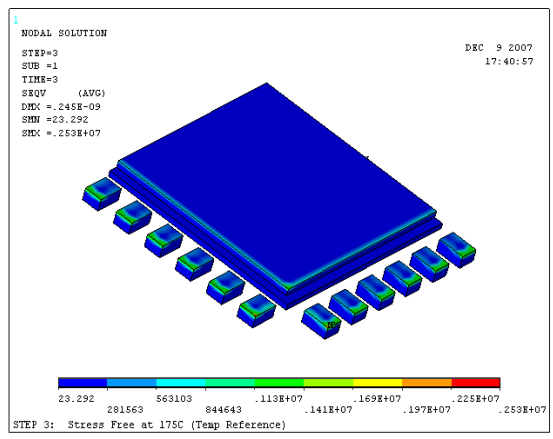

Step 3

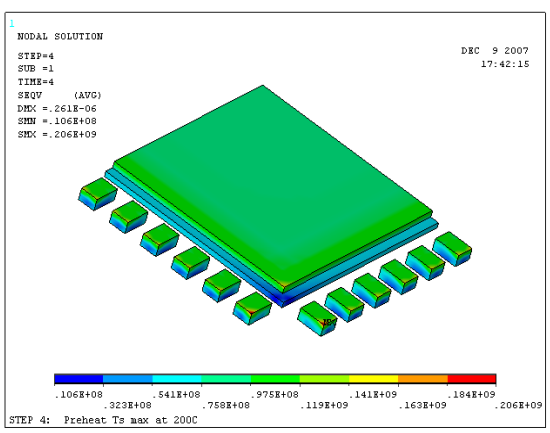

Step 4
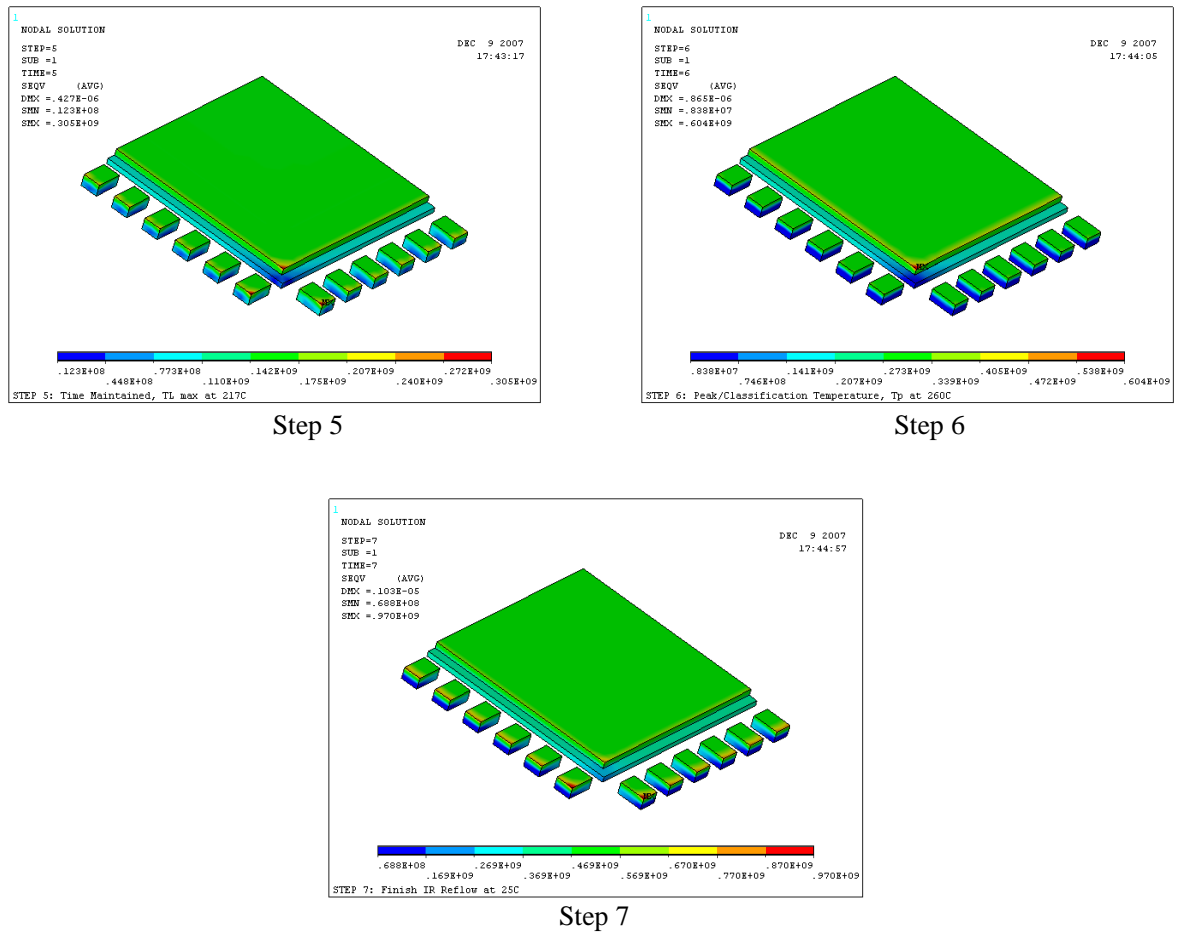

Fig. 8: Results of the von-Mises contour on QFN package used leadframe thickness of $0.15 \mathrm{~mm}$ for etch steps condition 
Am. J. Applied Sci., 6 (4): 616-625, 2009

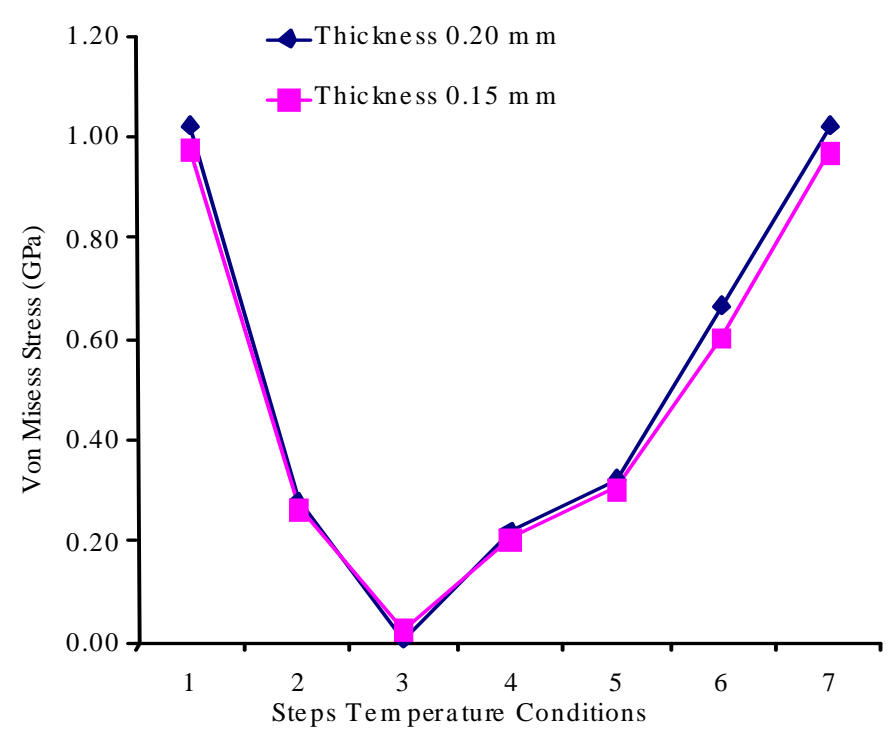

Fig. 9: A plot of von Mises stress for different leadframe thickness versus the reflow stages

\section{CONCLUSION}

A study on the packaging process induced initial stress-state of a selected QFN package was presented in this research. The IR reflow are considered to be the temperature dependent elastic-plastic and rate dependent creep behavior. The viscoelastic behaviour of EMC during and after reflow process was subsequently simulated and it was then followed by temperature cycling simulations.

From the simulation results, it was found that a thinner. The stress distribution that was obtained for the second leadframe design $(0.15 \mathrm{~mm}$ thickness $)$ was below the Young's modulus value. From the simulation result, it is suggested that the reliability of $0.15 \mathrm{~mm}$ and $0.20 \mathrm{~mm}$ leadframe thickness were almost similar compared deformation on displacement and von Misess stress.

In order to make some modification for either by material selection or the package dimension, it is suggested that the selection of select a material must be based on Coefficients of Thermal Expansion (CTE) of a material. The residual stresses can also be occurred due to the mismatch between dissimilar materials during the reflow soldering process. At the end of the reflow process, the tensile stress of centre surface in EMC is at the highest level, the centre surface of leadframe is the possible failure site for delamination and die-crack.

\section{ACKNOWLEDGEMENT}

This study was supported by the Malaysia Government and Universiti Kebangsaan Malaysia, under the IRPA grant of 03-01-01-0088-PR0075/09-08. Special thanks also conveyed to AIC Semiconductor Sdn. Bhd. for their assistance in providing experimental facilities.

\section{REFERENCES}

1. Hao, X., L. Qin, D. Yang and S. Liu, 2003. Thermal-mechanical stress and fatigue failure analysis of A PBGA. Proceeding of the 5th International Conference on Electron. Packaging Technology, Oct. 28-30, Shanghai, China, pp: 438442. DOI: 10.1109/EPTC.2003.1298776.

2. Pang, H.L.J., Y.P. Wang, X.Q. Shi and Z.P. Wang, 1998. Sensitivity Study of temperature and strain rate dependent properties on solder joint fatigue life. 9th International Conference on Electron. Materials and Packaging, July 6-9, Hong Kong, China, $\quad$ pp: 184-189. DOI: 10.1109/EPTC.1998.755999.

3. Darveaux, R. and K. Banerji, 1992. Constitutive relations for tin-based solder joints. IEEE Trans. Comp. Hyb. Manufac. Tech., 15: 1013-1024. DOI: 10.1109/33.206925.

4. Sham, M.L., J.K. Kim and J.H. Park, 2003. Viscoelastic Properties of Underfill for Numerical Analysis of Flip Chip Packages. 53rd Electron. Components and Technology Conference, May 2730, New Orleans, Louisiana, USA., pp: 560-566. http://ieeexplore.ieee.org/xpl/freeabs_all.jsp?arnum ber $=1216336$. 
5. Yan, C., Q.H. Qin and Y.W. Mai, 2001. Nonlinear analysis of plastic ball grid array solder joints. J. Mater. Sci. Mater. Electron., 12: 667-673. DOI: 10.1023/A:1012806218825.

6. Lee, J.G., A. Telang, K.N. Subrarnanian and T.R. Bieler, 2002. Modeling thermalmechanical fatigue behavior of Sn-Ag solder joints. J. Electron. Mater., 31: 1152-1159. DOI: 10.1007/s11664-0020004-z.

7. Solid State Technology Association (JEDEC), 2004. Joint industry standard: Moisture/Reflow Sensitivity Classification for Nonhermetic Solid State Surface Mount Devices. IPC/JEDEC J-STD020C July 2004, 1-20.
8. Benson, J., M. Kwoka and R. Claudio, 2004. PCB Land Pattern Design and Surface Mount Guidelines for QFN (MLFP) Packages. http://www.kionix.com/TechNotes/Intersil\%20TB389.pdf

9. Kwoka, M. and J. Benson, 2008. PCB Land Pattern Design and Surface Mount Guidelines for QFN Packages.

http://www.intersil.com/data/tb/TB389.pdf. 